\title{
Room and Elevated Temperature Tensile Properties of Single Tow Hi- Nicalon, Carbon Interphase, CVI SiC Matrix Minicomposites
}

\author{
J. Martínez-Fernández \\ Dpto. de Física de la Materia Condensada \\ Universidad de Sevilla, Spain \\ G. N. Morscher* \\ Case Western Reserve University \\ Cleveland, $\mathrm{OH}$
}

\begin{abstract}
Single tow Hi-Nicalon ${ }^{\mathrm{TM}}, \mathrm{C}$ interphase, CVI SiC matrix minicomposites were tested in tension at room temperature, $700^{\circ} \mathrm{C}, 950^{\circ} \mathrm{C}$, and $1200^{\circ} \mathrm{C}$ in air. Monotonic loading with modal acoustic emission monitoring was performed at room temperature in order to determine the dependence of matrix cracking on applied load. Modal acoustic emission was shown to correlate directly with the number of matrix cracks formed. Elevated temperature constant load stress-rupture and low-cycle fatigue experiments were performed on precracked specimens. The elevated temperature rupture behavior was dependent on the precrack stress, the lower precrack stress resulting in longer rupture life for a given stress. It was found that the rupture lives of $\mathrm{C}$-interphase Hi-Nicalon ${ }^{\mathrm{TM}}$ minicomposites were superior to $\mathrm{C}$-interphase Ceramic Grade Nicalon ${ }^{\mathrm{TM}}$ minicomposites and inferior to those of BN-interphase Hi-Nicalon ${ }^{\mathrm{TM}}$ minicomposites.
\end{abstract}

\section{INTRODUCTION}

The poor intermediate temperature tensile-rupture behavior in air of ceramic grade Nicalon ${ }^{\mathrm{TM}}$ (NIC) ${ }^{* *}$ reinforced CVI SiC matrix composites with carbon interphases has been demonstrated over temperatures ranging from 425 to $1000^{\circ} \mathrm{C}$ [1-7]. The time to failure for

\footnotetext{
- Resident Research Associate at NASA Glenn Research Center, Cleveland, OH.

*Nippon Carbon, Tokyo, Japan
} 
all these studies corresponds to a stress exponent, $n$, of approximately $1 / 4$ [4], where time to failure, $t$, is directly proportional to composite stress, $\sigma$, to the power $n$ :

$$
\mathrm{t} \alpha \sigma^{-\mathrm{n}}
$$

This corresponds to a rupture strength degradation of over $70 \%$ for rupture times less than 10 hours. Two mechanisms have been put forward for the reduction in strength of the $\mathrm{NIC/SiC}$ system with $\mathrm{C}$ interphases: the increase in effective gage length from carbon volatilization [3] and the flaw size increase due to oxide scale growth [4] on the surface of the fibers. The latter mechanism would predict a stress exponent of $1 / 4$ assuming parabolic oxide growth at intermediate temperatures.

However, this strength degradation at temperature, in air, and at stress is far more severe than could be accounted for from these two mechanisms. For example, if only one crack existed in the gage section of a NIC/SiC composite, the fully loaded gage length of the fibers could be approximated by:

$$
1=\sigma R / 2 f \tau
$$

where $R$ is the fiber radius, $f$ is the volume fraction of load-bearing fibers, and $\tau$ is the interfacial shear strength [8]. For the case where $\sigma$ equals $240 \mathrm{MPa}$, f equals $0.16, \tau$ equals $10 \mathrm{MPa}$, and assuming a Weibull modulus $\mathrm{m}$ for individual fiber failure equal to 5 , the maximum decrease in strength due to an increase in gage length $(12 \mathrm{~mm}$ for the hot zone in the reference 2 study) would be $\sim 45 \%$. If more than one crack were in the hot zone of the furnace the degradation in rupture strength due to this mechanism would be less. In addition, if the oxide scale was related to the flaw size, one would expect an increase in flaw size (oxide scale thickness) of approximately one order of magnitude if the rupture strength was reduced from 2000 to $500 \mathrm{MPa}$ (a $75 \%$ decrease) over 100 hours at $700^{\circ} \mathrm{C}$, assuming a $\mathrm{K}_{\mathrm{IC}}$ of 2[9]. For the reference 2 study, $\mathrm{SiO}_{2}$ scales were not detectable on the fiber surfaces at these low temperatures, even though the fiber fracture mirrors were observed to increase commensurate with the degree of minicomposite rupture strength loss. Therefore, it is evident that the mechanisms causing $\mathrm{NIC/SiC}$ rupture with carbon 
interphases include a flaw growth or flaw creation mechanism in addition to the two already mentioned.

It is likely that the surface of the NIC fiber may have been modified during CVI SiC infiltration. Naslain [10] describes four NIC/C/CVI SiC composite scenarios where the surface of the Si-C-O containing NIC fibers are altered after CVI SiC composite fabrication. All four scenarios have a complex carbon-rich layer on the fiber surface in between the CVI deposited carbon layer and the $\mathrm{Si}-\mathrm{C}-\mathrm{O}$ fiber. In some cases $\mathrm{SiO}_{2}$ is present and in others it is not depending on the CVI approach taken and/or a fiber pretreatment. Nevertheless, local carbon rich areas at the fiber surface are present that would oxidize during rupture testing. In other words, a mechanism due to surface recession or "pit formation" as a result of the oxidation of carbon layers or local carbon rich regions on the fiber surface could lead to rapid strength loss. This type of mechanism better explains the observed rapid rupture strength loss with time for $\mathrm{NIC/C} / \mathrm{SiC}$ composites. It is not known if the more thermally stable Hi-Nicalon ${ }^{\mathrm{TM}}(\mathrm{HN})$ fibers with $\mathrm{C}$ interphases would undergo similar degradation after CVI SiC processing.

In the earlier study [2] the minicomposite tensile stress rupture properties of NIC reinforced $\mathrm{SiC}$ with a BN interphase had superior elevated temperature stress-rupture life in air compared to $\mathrm{C}$ interphase minicomposites. This has also been shown for woven $\mathrm{NIC} / \mathrm{SiC}$ composites tested in flexure [11]. It was suggested in reference 2 that the $\mathrm{BN}$ interphase $\mathrm{NIC} / \mathrm{SiC}$ rupture behavior was superior to $\mathrm{C}$ interphase $\mathrm{NIC} / \mathrm{SiC}$ because of the formation of a measurable oxide layer $\left(\sim 0.5\right.$ micron at $700^{\circ} \mathrm{C}$ after 12 hours $)$ on the fibers that had a BN interphase. This was due to the enhanced oxidation of $\mathrm{SiC}$ when in contact with $\mathrm{BN}$ [12]. This oxide layer, which was predominantly $\mathrm{SiO}_{2}$, protected the fibers from the strength degrading mechanism of the NIC fibers when directly exposed to the environment as was the case for $\mathrm{C}$ interphase $\mathrm{NIC} / \mathrm{SiC}$. The presence of thick oxide scales on fibers in $\mathrm{BN}$ interphase $\mathrm{NIC/SiC}$ causing only minimal strength degradation $(\mathrm{n} \sim 50)$ also is further evidence against the oxide scale mechanism discussed above for $\mathrm{NIC} / \mathrm{SiC}$ with $\mathrm{C}$ interphases. It was also shown in reference 2 that the rupture behavior of $\mathrm{HN} / \mathrm{BN} / \mathrm{SiC}$ minicomposites were superior to NIC/BN/SiC minicomposites in air.

Unfortunately, in the earlier study, $\mathrm{HN} / \mathrm{SiC}$ minicomposites with $\mathrm{C}$ interphases were not studied. Since HN is a more thermally stable fiber than NIC, it may be expected that 
$\mathrm{HN} / \mathrm{SiC}$ with $\mathrm{C}$ interphases is not as susceptible to severe rupture strength degradation as $\mathrm{NIC/SiC}$ with $\mathrm{C}$ interphases. Thus, the question remains, how much worse, if at all, is $\mathrm{C}$ interphase $\mathrm{HN} / \mathrm{SiC}$ in rupture than $\mathrm{BN}$ interphase $\mathrm{HN} / \mathrm{SiC}$ ? Therefore, the impetus for this work was to determine the rupture behavior of $\mathrm{HN} / \mathrm{SiC}$ minicomposites with $\mathrm{C}$ interphases to provide a comparison for $\mathrm{HN} / \mathrm{SiC}$ minicomposites with $\mathrm{BN}$ interphases as well as $\mathrm{NIC} / \mathrm{SiC}$ minicomposites with $\mathrm{C}$ interphases.

\section{EXPERIMENTAL PROCEDURE}

Tows of $500 \mathrm{HN}$ fibers were used to fabricate the minicomposites studied in this work. The tows were mounted on graphite racks, coated with carbon and then composited with $\mathrm{SiC}$ by chemical vapor deposition (Hyper-Therm Inc., Huntington Beach California). The fiber volume fraction $(0.16 \pm 0.01)$ and minicomposite cross-sectional area was determined based on the measured or estimated weights and densities of the minicomposite constituents [13]. The observation of the minicomposite polished cross sections indicated that the carbon interface was uniform with an average thickness of $0.4 \mu \mathrm{m}$. The fracture surfaces of the minicomposites had a fibrous appearance, the $\mathrm{SiC}$ matrix being thicker on the outside, but more uniformly distributed in the interior than in the NIC fiber, Cinterphase minicomposites previously studied [2].

Room temperature tensile testing was performed using an universal testing machine (Model 4502, Instron, Canton, MA); the test set-up is described in detail elsewhere [2]. The minicomposites were mounted onto cardboard tabs with epoxy. Monotonic loading tensile tests were performed to determine the ultimate failure load and the optimum precrack load. Modal acoustic emission (AE) was monitored with sensors attached to the epoxy just above and below the minicomposite gage-section. The AE analyzer (Digital Wave Corporation, Englewood, $\mathrm{CO}$ ) recorded and digitized the true sound wave form for each event on both channels (sensors). The number of events and location of each event could then be determined once the speed of sound was estimated. The details of the $\mathrm{AE}$ analysis are included in the Appendix.

Constant-load stress rupture tests were run in a dead-weight load stress-rupture rig. A furnace was located at the center of the minicomposite. The total length of the furnace 
was $35 \mathrm{~mm}$ with a hot zone of $12 \mathrm{~mm}$. These tests were run at $700^{\circ} \mathrm{C}, 950^{\circ} \mathrm{C}$, and $1200^{\circ} \mathrm{C}$. The minicomposites were fully loaded before increasing the temperature at $100^{\circ} \mathrm{C} / \mathrm{min}$ up to the test temperature. The minicomposites were precracked at room temperature with loads of 119 or $126 \mathrm{~N}$, which corresponds to a composite stress of 280 or $295 \mathrm{MPa}$, respectively.

The fatigue tests were also run at $700^{\circ} \mathrm{C}, 950^{\circ} \mathrm{C}$, and $1200^{\circ} \mathrm{C}$ with the universal testing machine and same furnace set-up. The load was cycled from a minimum stress of 25-50 MPa to the peak stress. The loading frequency was $0.01 \mathrm{~Hz}(100 \mathrm{~s}$ per cycle) for all the experiments. For the fatigue tests, the load-cycle was begun after reaching the set temperature. The peak load was applied prior to and during heating just as for the rupture tests. The minicomposites were also precracked prior to the cyclic test at $280 \mathrm{MPa}$.

Some minicomposites were polished longitudinally after testing, and the crack spacing was measured by optical microscopy. The fracture surfaces were observed using a scanning electron microscope (SEM) JEOL 840A (JEOL, Tokyo, Japan).

\section{RESULTS}

\section{a) Room Temperature Mechanical Testing}

The load versus time curve for a typical monotonic loading experiment is shown in Figure 1. The curves are linear up to approximately $84.4 \mathrm{~N}$ (200 MPa composite stress), when matrix cracking starts to occur. The occurrence of $\mathrm{AE}$ events (also shown in Fig. 1) indicates that the change in slope is associated with matrix cracking. The cumulative number of $\mathrm{AE}$ events and the cumulative total energy increase at the same rate. The ultimate failure composite stress ranged from 280 to $350 \mathrm{MPa}$; however, most of the minicomposites (approximately 75\%) failed between $310-325 \mathrm{MPa}$, with an average strength of $317 \pm 26 \mathrm{MPa}$. The average ultimate strength of the fibers determined by the cross-sectional area of load-bearing fibers (fully loaded) was $2000 \pm 200 \mathrm{MPa}$. The strength of individual $\mathrm{HN}$ fibers (25.4 mm gage length) is $\sim 2800 \mathrm{MPa}$ whereas the average strength of as-produced tows of $\mathrm{HN}(25.4 \mathrm{~mm}$ gage length) is $\sim 1700 \mathrm{MPa}$ [14]. Based on equation 2, the actual fully-loaded gage length is on the order of 30 to $50 \mathrm{~mm}$, therefore, in comparison to single tow strength, no strength loss due to minicomposite fabrication occurred. 
Figure 2 shows the cumulative number of events recorded normalized by the gage length of the minicomposite specimen. The nature of $\mathrm{AE}$ activity was very consistent for the specimens tested. For several samples, the number of cracks was measured from polished longitudinal sections. The crack spacing was determined from the number of cracks counted over a given length of minicomposite. Table AI (Appendix) shows the nearly one-to-one correspondence between the number of highest energy events recorded and the estimated number of cracks in the gage section of the minicomposite.

\section{b) Elevated Temperature Mechanical Testing}

The data from the constant load stress-rupture experiments are plotted in Figure 3a and $3 \mathrm{~b}$ as the stress applied (if fibers were fully loaded) versus the time to rupture (the arrows indicate the minicomposite did not fail). These data are plotted together with previous data from C-NIC minicomposites (Fig. 3a) and BN-HN minicomposites (Fig. 3b) [2]. The C-HN minicomposites have longer survival times than the C-NIC minicomposites at $700^{\circ} \mathrm{C}$ although for higher loads the two curves tend to blend together. The C-HN minicomposites have shorter survival times than the $\mathrm{BN}-\mathrm{HN}$ minicomposites especially at 700 and $950^{\circ} \mathrm{C}$. All the samples broke in the hot region of the fumace. For these tests the minicomposites were precracked at $280 \mathrm{MPa}$ (composite stress).

Stress-rupture tests were also performed using a larger precrack load. In Figure 4 the C-HN data from Figure 3 (where a precrack load of $280 \mathrm{MPa}$ was used) are plotted compared with the data from samples precracked at $295 \mathrm{MPa}$. At $700^{\circ} \mathrm{C}$ and $950^{\circ} \mathrm{C}$ the time of survival decreases with increasing precrack load. At $1200^{\circ} \mathrm{C}$ this effect was not as pronounced as at the lower temperature tests. The use of a larger precrack load introduced a greater amount of scatter in the data. The precrack stresses of $280 \mathrm{MPa}$ (load of $119 \mathrm{~N}$ ) and $295 \mathrm{MPa}$ (load of $126 \mathrm{~N}$ ) correspond with $88 \%$ and $93 \%$ of the average strength respectively. The precrack load used in a previous work for C-NIC and BN-HN was $60 \%$ $(110 \mathrm{~N})$ and $78 \%(111 \mathrm{~N})$ of the average strength, respectively. Since the fraction of the average strength using the lower precrack load is closer to the previous ones, the results with the samples precracked at $280 \mathrm{MPa}$ were the ones used for comparison.

The results from the fatigue experiments are plotted in Figure 5 together with the stress rupture results from samples precracked at $280 \mathrm{MPa}$ (same precrack load). The time 
taken for the fatigue experiments is the total time under cyclic loading conditions. At $700^{\circ} \mathrm{C}$ the behavior is essentially the same as the constant load conditions. The minicomposite resistance to fatigue rapidly decreased at $950^{\circ} \mathrm{C}$. At this temperature the samples tested at the highest peak stress failed in the first or second fatigue cycle (for peak stresses over 75 $\mathrm{MPa}$, the stress on the fibers where fully loaded would be $500 \mathrm{MPa}$ ). For the tests run at $700^{\circ} \mathrm{C}$ and $950^{\circ} \mathrm{C}$, failure always occurred in the hot zone of the furnace. For all the tests run at $1200^{\circ} \mathrm{C}$ the failure occurred outside the hot zone region, about $2 \mathrm{~cm}$ from the center of the furnace. In these regions the temperature is approximately $900^{\circ} \mathrm{C}$ based on the temperature profile of the furnace. The data from these tests were very similar to the data from the tests run at $950^{\circ} \mathrm{C}$.

Some of the minicomposites did not fail after very long rupture times (e.g. 1000, 500 , and $400 \mathrm{MPa}$ for $700^{\circ} \mathrm{C}, 950^{\circ} \mathrm{C}$, and $1200^{\circ} \mathrm{C}$, respectively). These tests as well as some tests at shorter times were stopped before rupture and the retained strengths of the minicomposites were determined at room temperature. The general trend was higher rupture temperatures resulted in lower retained strength (Table $\mathrm{I}$.

\section{c) Microstructural characterization}

Figures 6 and 7 show the range of observed microstructural features observed on fracture surfaces after for C-HN minicomposite specimens tested between 700 and $1200^{\circ} \mathrm{C}$. Figure 6 shows a micrograph of a typical fracture surface for a stress-rupture test run at $700^{\circ} \mathrm{C}$. Due to the fibrous nature of these minicomposites fracture often occurs at different planar levels, although at each "level" the matrix fracture surfaces were flat. For short-term rupture $\left(t<0.1 \mathrm{hr}\right.$.) there was some fiber pullout. For longer rupture time at $700^{\circ} \mathrm{C}$ some regions of the minicomposite fracture surface showed relatively long pullout lengths (Fig. 6f). However, this increase in length was not uniform throughout the sample. Even though the carbon interphase was removed by oxidation resulting in a gap between the fiber and matrix.

At $1200^{\circ} \mathrm{C}$ the formation of $\mathrm{SiO}_{2}$ is more evident on the surface of the CVI SiC matrix and in the gap that was formerly the $\mathrm{C}$ interphase (Figure 7). Two different regions are noted in this sample. The higher magnification insets in Figure 7 show that the crack had propagated through part of the sample prior to failure, where the matrix region is 
clearly oxidized. Part of the failure matrix crack surface was not oxidized. Apparently, the non-through thickness matrix crack propagated through an uncracked section of matrix at ultimate minicomposite failure. However, the $\mathrm{C}$ interphase was removed and fibers were strongly bonded to the matrix in this region, presumably from oxidation through another matrix crack and along the vacated interphase channel. $\mathrm{A} \mathrm{SiO}_{2}$ scale did not cover the fiber fracture surfaces because the fibers did not fail until minicomposite ultimate failure.

The fracture surfaces of the stress-rupture test performed at $950^{\circ} \mathrm{C}$ (not shown) contain little if any fiber pull out even for very short-term rupture because the oxide reaction product nearly fills the gap left by the vacated interphase. Bonding between the fiber and matrix was obviously strong.

\section{DISCUSSION}

\section{a) Stress rupture: Comparison with previous data.}

In Figure 3a the stress rupture data at $700^{\circ} \mathrm{C}$ is compared with previous data from NIC minicomposites with a carbon interphase. In both cases the minicomposite rupture is due to fiber degradation, as the matrix-fiber bonding associated with $\mathrm{SiO}_{2}$ formation is negligible. For this reason the better properties of C-HN versus C-NIC are clearly related with the better thermal stability of the $\mathrm{HN}$ fibers. The stress-rupture resistance of the $\mathrm{C}-\mathrm{HN}$ minicomposites, however, is inferior to BN-HN (Fig. 3b).

In order to compare minicomposite data at different temperatures and fiber fast fracture data, the Larson-Miller (LM) approach $[15,16]$ was used. In this empirical approach the effect of temperature and time are combined in one parameter:

$$
q=T\left(\log t_{R}+C\right)
$$

where $T$ is the temperature (in $\mathrm{K}$ ), $\mathrm{t}_{\mathrm{R}}$ the time (in hr), and $\mathrm{C}$ the Larson-Miler constant, which was found to be 22 for both NIC and HN fibers [17]. In Figure 8 data obtained in this and previous studies [2] are plotted as the applied rupture stress versus the LM parameter (q). The room temperature (RT) failure stress was $2020 \mathrm{MPa}, 2300 \mathrm{MPa}$, and $2100 \mathrm{MPa}$ for C-HN, C-NIC, and BN-HN respectively. Also plotted in Figure 8 is the data for stressrupture of as-produced $\mathrm{HN}$ fibers [17]. The room temperature strength of the HN fibers studied in reference 15 was $2800 \mathrm{MPa}$. It was shown in reference 16 that HN-BN 
minicomposites with different RT strengths had the same rupture behavior at low and high temperatures as the fibers (i.e. same slope on $\ln (\sigma)$ vs. q). However, the absolute rupture strengths were lower for the lower RT strength minicomposites in proportion to the absolute strength of the as-produced fibers. Therefore, normalizing the RT as-produced fiber strength to $2100 \mathrm{MPa}$ was used for comparison of the as-produced fiber rupture properties with the minicomposite stress-rupture data. If the fiber degradation is merely due to the fiber degradation observed for as-produced fibers, the minicomposite rupture data should decrease the same as the fiber data if the starting strength of the fibers were $2100 \mathrm{MPa}$.

The C-HN and BN-HN minicomposite properties are closer to the individual fiber rupture behavior at low and high temperatures. At intermediate temperatures there is degradation of the minicomposite behavior compared to the individual fiber because of the embrittlement associated with fiber-matrix bonding due to $\mathrm{SiO}_{2}$ formation. Figure 8 shows the improvement in rupture properties of $\mathrm{BN}$ interphase over the $\mathrm{C}$ interphase. It is also clear from Figure 8 that C-NIC suffered more serious fiber degradation due to oxidation than C-HN.

At $700^{\circ} \mathrm{C}$ the loss of carbon by oxidation results in long load-bearing gage lengths for the HN fibers. The oxidation kinetic of a continuous carbon phase was studied by Eckel et al. [19]. If we assume that the oxidation is controlled by the diffusion of oxygen, the recession length $(\xi)$ is:

$$
\xi=k_{p}^{1 / 2} t^{1 / 2}
$$

where $k_{p}$ is the parabolic rate constant and the time. For an opening of $0.4 \mu \mathrm{m}$ (carbon interface thickness), $\mathrm{k}_{\mathrm{p}}$ is $10^{-8} \mathrm{~m}^{2} \mathrm{~s}^{-1}$ [19], and approximately $6 \mathrm{~mm}$ of carbon interphase length would be lost in about 1 hour. This would correspond to the entire hot zone gage length for a minicomposite with one crack in the hot zone region. The fiber length exposed to the maximum load when the interphase was completely oxidized was about 25 times larger than the fiber length if there was no oxidation of the interface (assuming one crack, as in the Introduction). This difference in load-bearing length will result in a decrease in strength of $47 \%$ to $28 \%$ for a Weibull modulus from 5 to 10 . For more than one crack in the hot zone, a smaller reduction in strength would occur. This gage-length effect best explains the decrease of strength of $\mathrm{C}-\mathrm{HN}$ compared with $\mathrm{BN}-\mathrm{HN}$ since the rupture strength of the 
C-HN minicomposites are approximately $25 \%$ reduced compared to the shorter gage-length loaded BN-HN minicomposites.

The presence of fibers with no pullout on the fracture surface was observed for some of the fibers on the minicomposite fracture surfaces tested at $700^{\circ} \mathrm{C}$ and occurred for all of the fibers on the minicomposite fracture surfaces tested at $950^{\circ} \mathrm{C}$. This indicates that strong bonding of the fibers to the matrix was a factor at these temperatures. When one or more fibers failed at or away from the matrix crack, the added load to the neighboring fibers in the matrix crack would be enhanced due to strong bonding resulting in local stressconcentrations. This causes most of the fibers to preferentially fail in the plane of the matrix crack. The longer recession distance with $\mathrm{C}$ interphases not only increases the fiber gage length, it also allows fibers to bond more quickly compared to BN interphases. The $\mathrm{BN}$ interphase only recesses a few microns separating the fiber from the matrix. For $\mathrm{C}$ interphase minicomposites, after total $\mathrm{C}$ interphase removal, the fibers are free to move towards and contact the matrix.

At $1200^{\circ} \mathrm{C}, \mathrm{SiO}_{2}$ formation is extensive. The stress-rupture properties appear to be controlled by the creep of the fibers and are similar for both minicomposite systems. The differences between $\mathrm{C}$ and $\mathrm{BN}$ interphase $\mathrm{HN}$ minicomposites at $1200^{\circ} \mathrm{C}$ still could be due to a slower recession of the $\mathrm{BN}$ interface.

\section{b) Dependence of the stress-rupture behavior on precrack load}

The load-time curve of Figure 1 indicates that cracks are being created in the minicomposite up to failure. It is clear then that the increase of the precrack load from 280 to $295 \mathrm{MPa}$ implies an increase in the number of matrix cracks. Based on the direct relationship between the number of cracks and $\mathrm{AE}$ events (Table A1) and the number of events recorded for several samples as a function of load (Figure 2), there would be one or two cracks in the hot zone after the $119 \mathrm{~N}$ precrack load. For the $126 \mathrm{~N}$ precrack load, between 2 and 4 cracks would be estimated in the hot zone. A larger number of cracks cause faster oxidation of the entire interphase in the hot zone. This results in a larger length of the fiber holding the maximum load (at least for short tests), more environmental degradation of the fibers, and more locations for stress concentration associated with $\mathrm{SiO}_{2}$ formation and the strong bonding between fiber and matrix. All these factors would cause a 
decrease in the stress-rupture survival time. During the precrack loading step, it was rather common (approximately $25 \%$ of the cases) for composites to fail between 290 to $295 \mathrm{MPa}$. This indicates that, in addition to an increase in the crack density, a greater occurrence of fiber failure would be occurring in minicomposites precracked at $295 \mathrm{MPa}$ than at 280 $\mathrm{MPa}$, and could also contribute to the poorer stress-rupture behavior compared to samples precracked at $280 \mathrm{MPa}$ (Fig. 6). At $1200^{\circ} \mathrm{C}$ failure is dominated by the creep-rupture behavior of the fibers, explaining the smaller dependence of the survival time with precrack load for this temperature.

\section{c) Fatigue}

The results from fatigue experiments (Fig. 5) clearly indicate that it is at intermediate temperatures when the relative movement of matrix and fiber, due to fatigue, affect the survival time most dramatically. This is presumably due to the local concentration of stress during fatigue on the sites where the fiber and matrix are bonded because of the $\mathrm{SiO}_{2}$ formation. At $1200^{\circ} \mathrm{C}$ the minicomposite failed about $2 \mathrm{~cm}$ from the center of the furnace. In these regions the temperature is approximately $900^{\circ} \mathrm{C}$. This shows that the resistance to fatigue is worse at intermediate temperatures than at $1200^{\circ} \mathrm{C}$ even though a greater amount of oxide reaction product is formed at $1200^{\circ} \mathrm{C}$ in the matrix cracks than at intermediate temperatures. $\mathrm{SiO}_{2}$ at $1200^{\circ} \mathrm{C}$ does flow to some extent and may relieve some of the stress-concentrations produced at the fiber-SiO${ }_{2}$-matrix bond compared to lower temperatures where no relaxation of the glass product would be expected. At $700^{\circ} \mathrm{C}$ the fiber and matrix are not fully bonded as evidenced by the occurrence of fiber pullout (Figure 7) and the differences between fatigue and stress rupture are not as significant as at $950^{\circ} \mathrm{C}$.

\section{d) Retained strength}

The retained strengths at room temperature of C-HN minicomposites that did not fail during the rupture test are listed for C-HN and BN-HN [2] minicomposites in Table I. For rupture conditions at 700 and $900^{\circ} \mathrm{C}$, the retained strength of $\mathrm{BN}-\mathrm{HN}$ minicomposites are significantly better than for $\mathrm{C}-\mathrm{HN}$ minicomposites. This is most likely due to the slower recession of $\mathrm{BN}$ which enables the fibers to be separated from the $\mathrm{SiC}$ matrix. 
Higher temperatures are required to form enough oxide reaction product, for BN-HN minicomposites, in order to fill the gap between the fibers and matrix. In comparison, the fibers in $\mathrm{C}-\mathrm{HN}$ minicomposites are observed to be in intimate contact with the matrix shortly after the $\mathrm{C}$ layer was removed by oxidation at $700^{\circ} \mathrm{C}$ (e.g. Figure 6). After $1200^{\circ} \mathrm{C}$ rupture conditions, the vacated interphases are completely filled by the glass reaction products for both systems and the retained strength data for C-HN and BN-HN minicomposites are nearly identical.

\section{CONCLUSIONS}

The stress rupture properties of $\mathrm{HN}$ fiber-reinforced CVI-SiC minicomposites with carbon interphase were studied at temperatures ranging from $700^{\circ} \mathrm{C}$ to $1200^{\circ} \mathrm{C}$. The stressrupture lives of C-HN are by far superior to C-NIC presumably due to the lack of fiber decomposition/reaction during CVI SiC processing that occurs for NIC fibers. This study demonstrates that $\mathrm{C}-\mathrm{HN}$ minicomposites have worse mechanical properties at $700^{\circ} \mathrm{C}$ and $950^{\circ} \mathrm{C}$ than the BN-HN minicomposites previously studied, due to the removal of carbon interphases and the ease with which fibers bond to the matrix. Therefore, BN interphases are more environmentally stable in the intermediate temperature regime. At $1200^{\circ} \mathrm{C}$ the improvement of the BN interphase over the carbon interphase was not quite as significant as at the lower temperatures; the stress rupture and fatigue properties predominantly being controlled by the fiber properties. This study also shows that $\mathrm{AE}$ emission can be used on this system as a reliable quantitative method to monitor damage in this system.

\section{APPENDIX: ACOUSTIC EMISSION DETECTION AND ANALYSIS OF MINICOMPOSITE TENSILE TESTS}

The AE set-up was similar to previous studies [20,21]. However, wide-band sensors were used to detect $\mathrm{AE}$ activity in order to capture and digitize the waveform. This approach provides greater accuracy in sorting out gage events and correlating individual events with physical sources [20]. Figure A1 shows a schematic of the tensile test. For 
most tests, only two wide band $(50 \mathrm{kHz}$ to $2 \mathrm{MHz})$ sensors* were attached with alligator clips to the epoxy. For two experiments, four wide band sensors were attached to the epoxy, two wide-band and two resonant frequency" (the same as used in the earlier studies). The data was collected on a Digital Wave (Englewood, Colorado) Fracture Wave Detector. After the test, the same software used to collect the data was used to analyze the data. For experiments with only two sensors, 100 to 200 events were recorded. For experiments with four sensors, up to 600 events were recorded because the resonant frequency sensors were much more sensitive, especially to lower frequency $\mathrm{AE}$.

Post-test analysis consisted first of determining the speed of sound through the sample in order to locate the sources of the AE events and to sort out events which occurred outside of the gage section. Pencil-lead breaks had been performed prior to a tensile test on the epoxy of an undamaged specimen outside of the sensors, so that the sound waves produced by the fracture of the pencil-lead traveled from one sensor to the next, and the $\mathrm{AE}$ data was saved on a separate file. The maximum difference in time of arrival, $\Delta t_{x}$, from one sensor to the next was determined from the first peak of the sound wave (extensional wave) received on both sensors from the lead-break event [21]. As a composite forms matrix cracks during testing the elastic modulus decreases and the speed of sound decreases resulting in an increase in $\Delta \mathrm{t}_{\mathrm{x}}$. For the tensile experiment $\mathrm{AE}$ data, the maximum difference in time of arrival was determined as a function of load and the speed of sound determined from the distance between the two sensors divided by $\Delta \mathrm{t}_{\mathrm{x}}$. Figure $\mathrm{A} 2$ shows the decrease in speed of sound of the extensional wave with load. This corresponds to the reduction in square root of the elastic modulus of the specimen as matrix cracking occurs.

The reduction in speed of sound is about $12 \%$. Since the speed of sound of the extensional wave is directly proportional to the square root of the elastic modulus, the elastic modulus is reduced by approximately $23 \%$. This is not as great a reduction in elastic modulus as in woven macrocomposites, $\sim 60 \%$, that reach a state of matrix crack saturation at relatively low composite stresses [21].

The events that were determined to occur outside of the gage section, i.e. events with difference in time of arrival, $\Delta \mathrm{t}$, equal to $\Delta \mathrm{t}_{\mathrm{x}}$, were removed from the data set. The

Model B1080, Digital Wave Corporation

" Model "Pico", Physical Acoustics Corporation 
location of each event along the gage length of the specimen could then be determined based on $\Delta t, \Delta t_{x}$, and the sensor which received the signal first [21]. Figure $A 3$ shows an example of event location as a function of load. The acoustic energy was determined for each event. It was observed that for the specimens where only two sensors were used, all of the $\mathrm{AE}$ event energies were within two decades of energy from one another. However, for the specimens where four sensors were used, the spread in $\mathrm{AE}$ energies was over three orders of magnitude. Also, many $\mathrm{AE}$ events were triggered by the more sensitive resonant frequency transducers. These events would never have triggered the wide-band sensors alone at the preamplification settings used. The events were therefore filtered according to $A E$ energy where only the two highest decades of energy events were used to relate to the accumulated damage. Table Al shows the event statistics along with the measured crack spacings for five specimens. Note the excellent agreement between the estimated number of cracks over the entire gage length of the samples compared to the highest two orders of magnitude $\mathrm{AE}$ energy events. The cumulative number and energies of the sorted $\mathrm{AE}$ events were used for Figures 2 and 3.

\section{REFERENCES}

1. F.E. Heredia, J.C. McNulty, F.W. Zok, and A.G. Evans, "Oxidation Embrittlement Probe for CeramicMatrix Composites," J. Am. Ceram. Soc., 78 [8] 2097-100 (1995)

2. G.N. Morscher, "Tensile Stress Rupture of SiCf/SiCm Minicomposites with Carbon and Boron Nitride Interphases at Elevated Temperatures in Air," J. Am. Ceram. Soc., 80 [8] 2029-42 (1997)

3. E. Lara-Curzio, M.K. Ferber, and P.F. Tortorelli, "Interface Oxidation and Stress-Rupture of Nicalon, TM/SiC CFCCs at Intermediate Temperatures," Key Engineering Materials Vols. 127-131, Trans Tech Publications, Switzerland, pp. 1069-1082 (1997)

4. E. Lara-Curzio, "Stress-Rupture of Nicalon/SiC Continuous Fiber Ceramic Matrix Composites in Air at 950 C," J. Am. Ceram. Soc., 80 [12] 3268-72 (1997)

5. P. Lipetzky, N.S. Stoloff, and G.J. Dvorak, "Atmospheric Effects on High-Temperature Lifetime of Ceramic Composites," Ceram. Eng. Sci. Proc., 18 [4] 355-362 (1997)

6. M.J. Verrilli, A.M. Calomino, and D.N. Brewer, "Creep-rupture Behavior of a Nicalon/SiC Composite," Thermal and Mechanical Test Methods and Behavior of Continuous-Fiber Ceramic Composites. ASTM STP 1309, eds. M.G. Jenkins, S.T. Gonczy, E. Lara-Curzio, N.E. Ashbaugh, and L. Zawada, ASTM pp. 158-175 (1997) 
7. T.E. Steyer, F.W. Zok, and D.P. Walls, "Stress Rupture of an Enhanced Nicalon ${ }^{\mathrm{TM}} / \mathrm{SiC}$ Composite at Intermediate Temperatures," J. Am. Ceram. Soc. 81 [8] 2140-46 (1998)

8. W.A. Curtin, "Theory of Mechanical Properties of Ceramic-Matrix Composites," J. Am. Ceram. Soc., 74 [11] 2837-45 (1991)

9. L. C. Sawyer, M. Jamieson, D. Brikowski, M.I. Haider, and R.T. Chen, "Strength, Structure, and Fracture Properties of Ceramic Fibers Produced from Polymeric Precursors: I, Base-Line Studies," J. Am. Ceram. Soc., 70 [11] 798-810 (1987)

10. R. Naslain, "Fiber-Matrix Interphases and Interfaces in Ceramic Matrix Composites Processed by CVI," Composite Interfaces, 1 [3] 253-286 (1993)

11. H.T. Lin and P.F. Becher, "Effect of Coating on Lifetime of Nicalon Fiber-Silicon Carbide Composites in Air," Mater. Sci. Eng., A231 143-150 (1997)

12. N.S. Jacobson, G.N. Morscher, D.R. Bryant, and R.E. Tressler, "High-Temperature Oxidation of Boron Nitride: II, Boron Nitride Layers in Composites," J. Am. Ceram. Soc., 82 [6] 1473-82 (1999)

13. G.N. Morscher, J. Martinez-Fernandez, and M.J. Purdy, "Determination of Interfacial Properties using a Single Fiber Microcomposite Test," J. Am. Ceram. Soc., 79, [4] 1083-91 (1996).

14. H.M. Yun and J.A. DiCarlo, "Thermomechanical Behavior of Advanced SiC Fiber Multifilament Tows," Ceram. Eng. Sci. Proc., 17 [4] 61-67 (1996)

15. F.R. Larson and J. Miller, "A Time-Temperature Relationship for Rupture and Creep Stresses," Trans. ASME, 74765 (1952)

16. J.B.Conway, "Numerical Methods for Creep and Rupture Analyses," Gordon and Breach, Science Publ., NY, $155-177$

17. H.M. Yun and J.A. DiCarlo, "Time/Temperature Dependent Tensile Strength of $\mathrm{SiC}$ and $\mathrm{Al}_{2} \mathrm{O}_{3}$-Based Fibers," Ceramic Transactions Vol 74, Advances in Ceramic-Matrix Composites III, eds. N.P. Bansal and J.P. Singh. pp. 17-26 (1996)

18. G.N. Morscher, "The Effect of Static and Cyclic Tensile Stress and Temperature on Failure for Precracked Hi-Nicalon/BN/CVD SiC Minicomposites in Air," Ceram. Eng. Sci. Proc., 18 [3] 737-745 (1997)

19. A. J. Eckel and J. D. Cawley, "Oxidation of a Continuos Carbon Phase in a Nonreactive Matrix". J. Am. Ceram. Soc. 78 [4] 972-80 (1995).

20. G.N. Morscher and J. Martinez-Fernandez, "Fiber Effects on Minicomposite Mechanical Properties for Several Silicon Carbide Fiber-Chemically Vapor-Infiltrated Silicon Carbide Matrix Systems," J. Am. Ceram. Soc., 82 [1] 145-55 (1999)

21. G.N. Morscher, "Modal Acoustic Emission of Damage Accumulation in a Woven SiC/SiC Composite," Comp. Sci. Tech., 59, 687-697 (1999) 


\section{FIGURE CAPTIONS}

Figure 1- Typical load vs. time curve for a monotonic loading experiment (specimen h3hc39). The number and cumulative energy (in arbritary units) of the AE events are also shown.

Figure 2: Number of events per millimeter versus load for several specimens tested at room temperature.

Figure 3- Minicomposite stress-rupture data. A) Compared with previous data on Nicalon minicomposites [1]. B) Compared with previous data on BN-HiNic minicomposites [2].

Figure 4- Minicomposite stress-rupture data for two different precrack loads.

Figure 5- Peak stress for fatigue experiments versus the survival time and comparison with stress-rupture data.

Figure 6- Typical fracture surface of C-HN minicomposite for stress ruptures at $700{ }^{\circ} \mathrm{C}(1183 \mathrm{MPa}, 5.9 \mathrm{hr})$.

Figure 7 - Fracture surface of a C-HN minicomposites for stress rupture at $1200^{\circ} \mathrm{C}(439 \mathrm{MPa}, 217 \mathrm{hrs})$.

Figure 8- Plot of the stress on fibers if fully loaded versus LM parameter. Previous data included [1]. See text for further discussion.

Figure A1: Schematic of room temperature tensile test.

Figure A2: Speed of sound versus load for specimen h $3 \mathrm{hc} 70$.

Figure A3- Location of the $\mathrm{AE}$ events along the length of the minicomposite (h3hc70) during a tensile monotonic loading test as a function of time. 


\section{Table I: Retained Strength at Room Temperature Data for $\mathrm{C}-\mathrm{HN}$ and $\mathrm{BN}-\mathrm{HN}$ Minicomposites}

\begin{tabular}{cccccc}
\hline Minicomposite & $\begin{array}{c}\text { Temperature, } \\
{ }^{\circ} \mathrm{C}\end{array}$ & $\begin{array}{c}\text { Applied } \\
\text { Stress, } \\
\mathrm{MPa}\end{array}$ & $\begin{array}{c}\text { Time at } \\
\text { Stress, } \\
\text { Hr. }\end{array}$ & $\begin{array}{c}\text { Retained } \\
\text { Strength, } \\
\text { MPa }\end{array}$ & $\begin{array}{c}\text { \% of As- } \\
\text { Produced } \\
\text { Strength* }\end{array}$ \\
\hline C-HN & 700 & 328 & 50 & 1389 & 69 \\
& 700 & 1099 & 358 & 1114 & 56 \\
& 950 & 590 & 94 & 683 & 34 \\
& 950 & 655 & 337 & 732 & 37 \\
& 950 & 655 & 337 & 766 & 38 \\
& 1200 & 439 & 3 & 512 & 26 \\
& 1200 & 439 & 17 & 544 & 27 \\
& 1200 & 439 & 162 & 491 & 25 \\
& & & & & \\
& 700 & 996 & 400 & 2260 & $\sim 100$ \\
& 816 & 951 & 324 & 1411 & 67 \\
& 950 & 1019 & 252 & 1630 & 77 \\
& 1200 & 328 & 882 & 525 & 25 \\
& 1200 & 385 & 965 & 792 & 38 \\
\hline
\end{tabular}

* The average ultimate strength (of the fibers if fully loaded) for as-produced C-HN $=2000 \mathrm{MPa}$ and for asproduced $\mathrm{BN}-\mathrm{HN}=2100 \mathrm{MPa}$. 


\section{Table A1: AE and Matrix Crack Data for Several Room Temperature Tested Minicomposites}

\begin{tabular}{|c|c|c|c|c|c|c|c|}
\hline Specimen & $\begin{array}{c}\text { Gage } \\
\text { Length, } \\
\mathbf{m m}\end{array}$ & $\begin{array}{c}\text { Speed of } \\
\text { Sound } \\
\mathrm{m} / \mathbf{s}\end{array}$ & $\begin{array}{c}\text { Number } \\
\text { of Events }\end{array}$ & $\begin{array}{c}\text { Failure } \\
\text { Load, N }\end{array}$ & $\begin{array}{c}\text { Crack } \\
\text { spacing, } \\
\mathbf{m m}\end{array}$ & $\begin{array}{c}\text { No. of Events } \\
\text { With Highest 2 } \\
\text { Decades of AE } \\
\text { Energy }\end{array}$ & $\begin{array}{c}\text { Number of } \\
\text { Cracks In } \\
\text { Gage } \\
\text { Length }\end{array}$ \\
\hline $\mathrm{h} 3 \mathrm{hc39}$ & 140 & 13861 & 212 & 151 & - & 135 & - \\
\hline $\mathrm{h} 3 \mathrm{~h} 640$ & 158 & 15192 & 579 & 152 & 0.56 & 238 & 250 \\
\hline $\mathrm{h} 3 \mathrm{hc70}$ & 160 & 11851 & 149 & 143 & 1.05 & 149 & 133 \\
\hline $\mathrm{h} 3 \mathrm{~h} \mathrm{~h} 76$ & 168 & 13228 & 132 & 143 & 0.96 & 132 & 146 \\
\hline $\mathrm{h} 3 \mathrm{hc77}$ & 170 & 12500 & 87 & 138 & 1.67 & 87 & 84 \\
\hline
\end{tabular}

* Extensional wave 


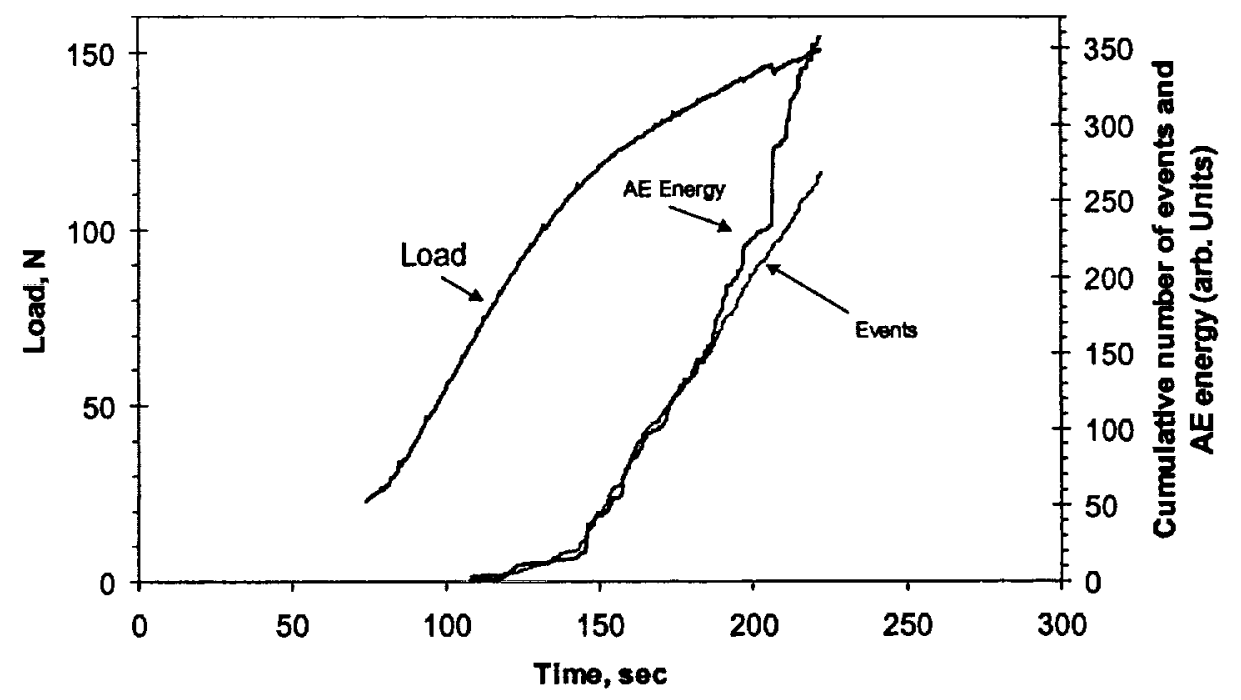

Fig. 1- Typical load vs. time curve for a monotonic loading experiment (specimen h3hc39). The number and cumulative energy (in arbritary units) of the AE events are also shown. 


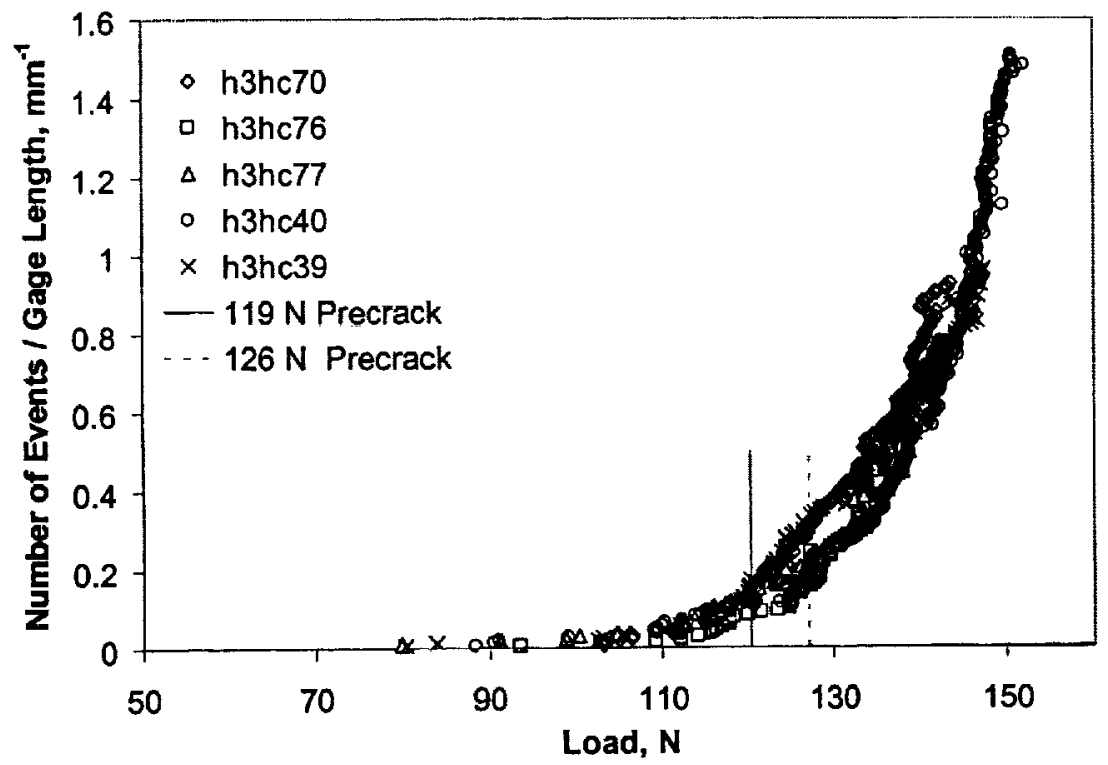

Figure 2: Number of events per millimeter versus load for several specimens tested at room temperature. 


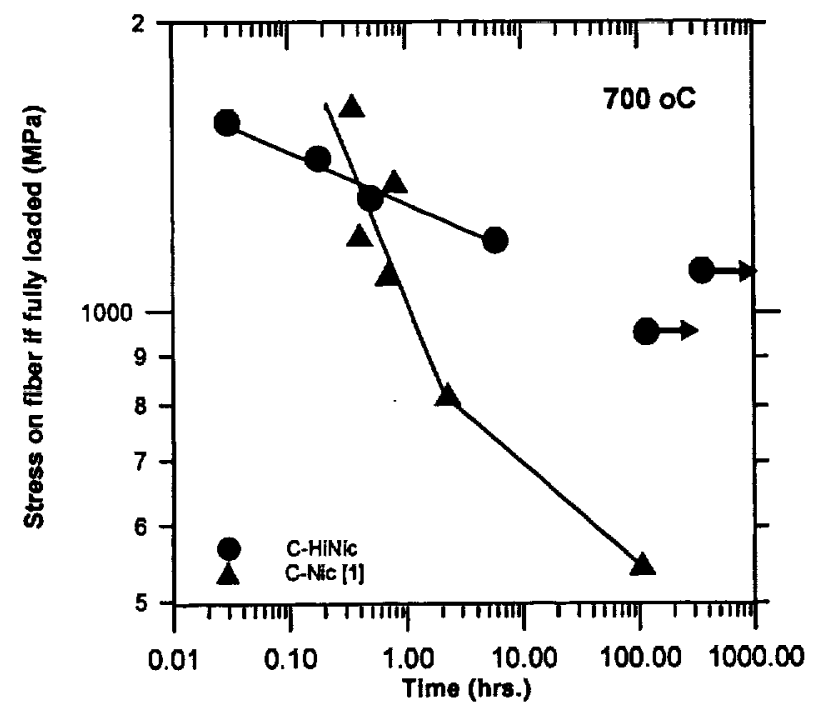

(a)

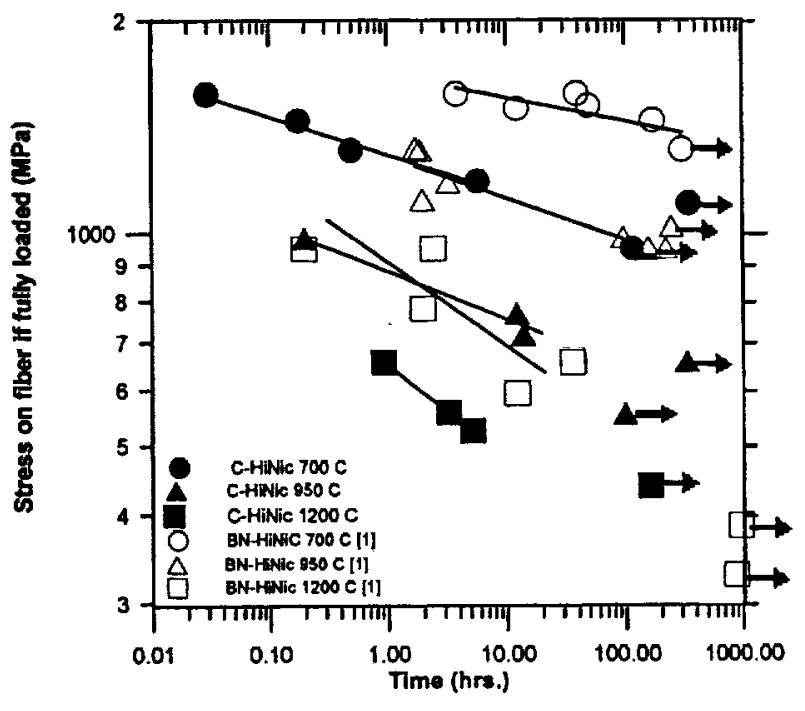

(b)

Figure 3- Minicomposite stress-rupture data. A) Compared with previous data on Nicalon minicomposites [2]. B) Compared with previous data on $\mathrm{BN}-\mathrm{HiNic}$ minicomposites [2]. 


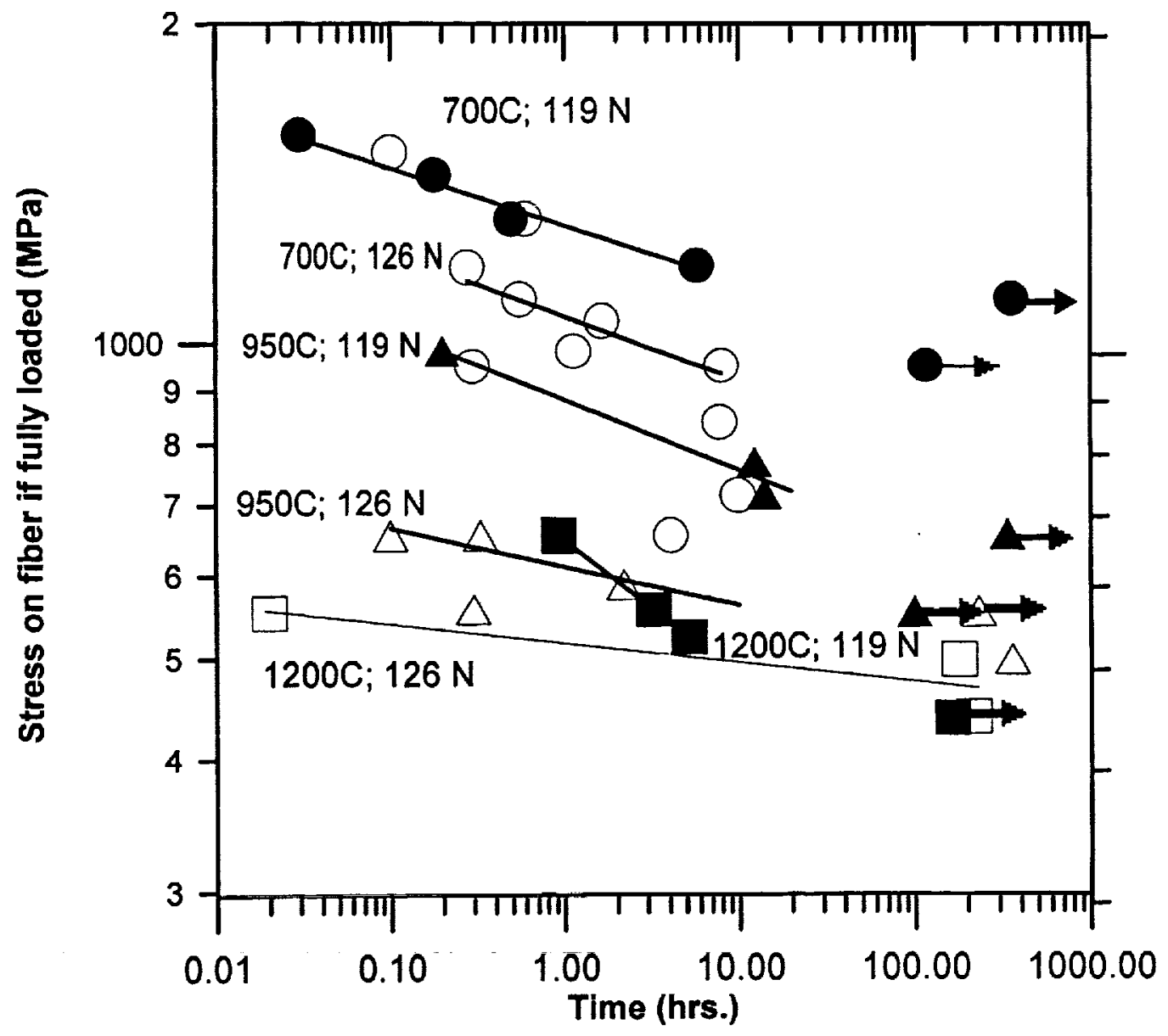

Figure 4- Minicomposite stress-rupture data for two different precrack loads. 


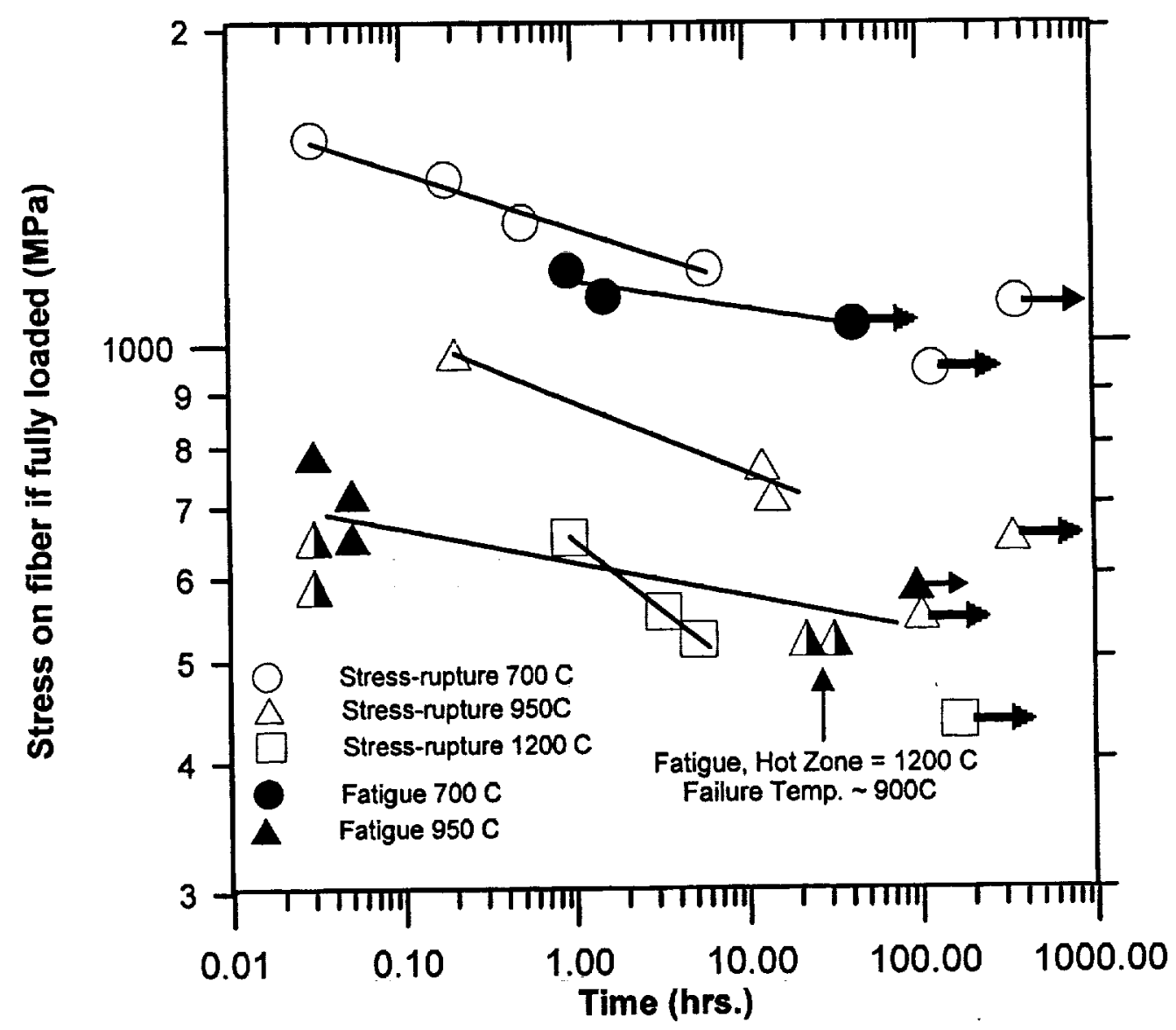

Fig. 5- Peak stress for fatigue experiments versus the survival time and comparison with stress-rupture data. 


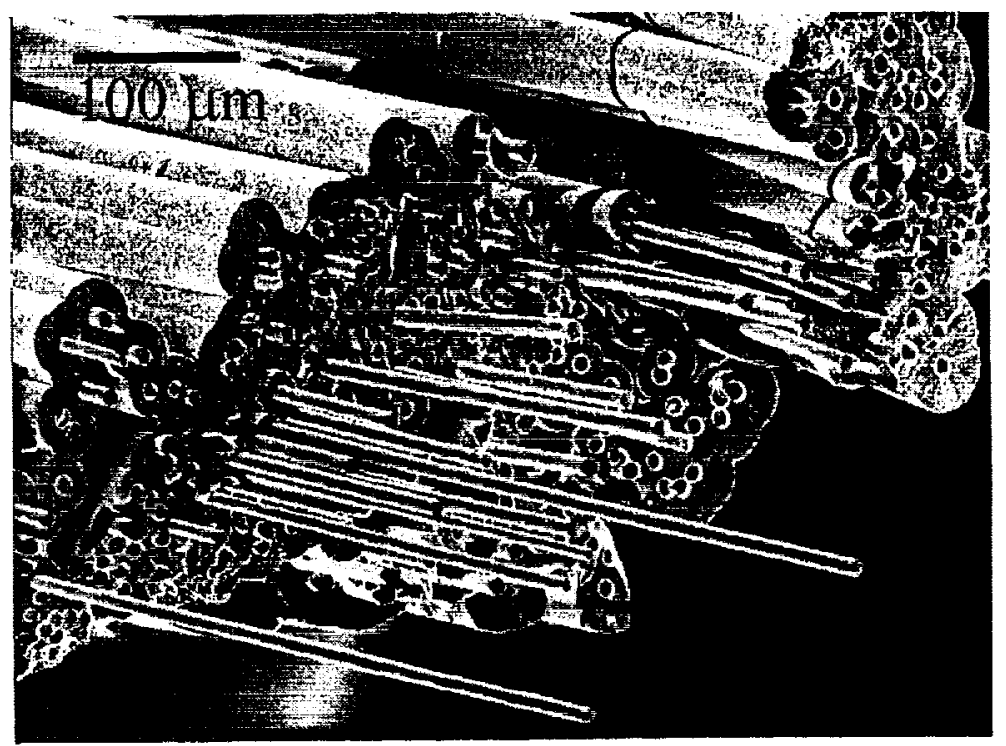

Fig. 6- Typical fracture surface of C-HN minicomposite for stress rupture at $700{ }^{\circ} \mathrm{C}(1183 \mathrm{MPa}, 5.9 \mathrm{hr})$. 


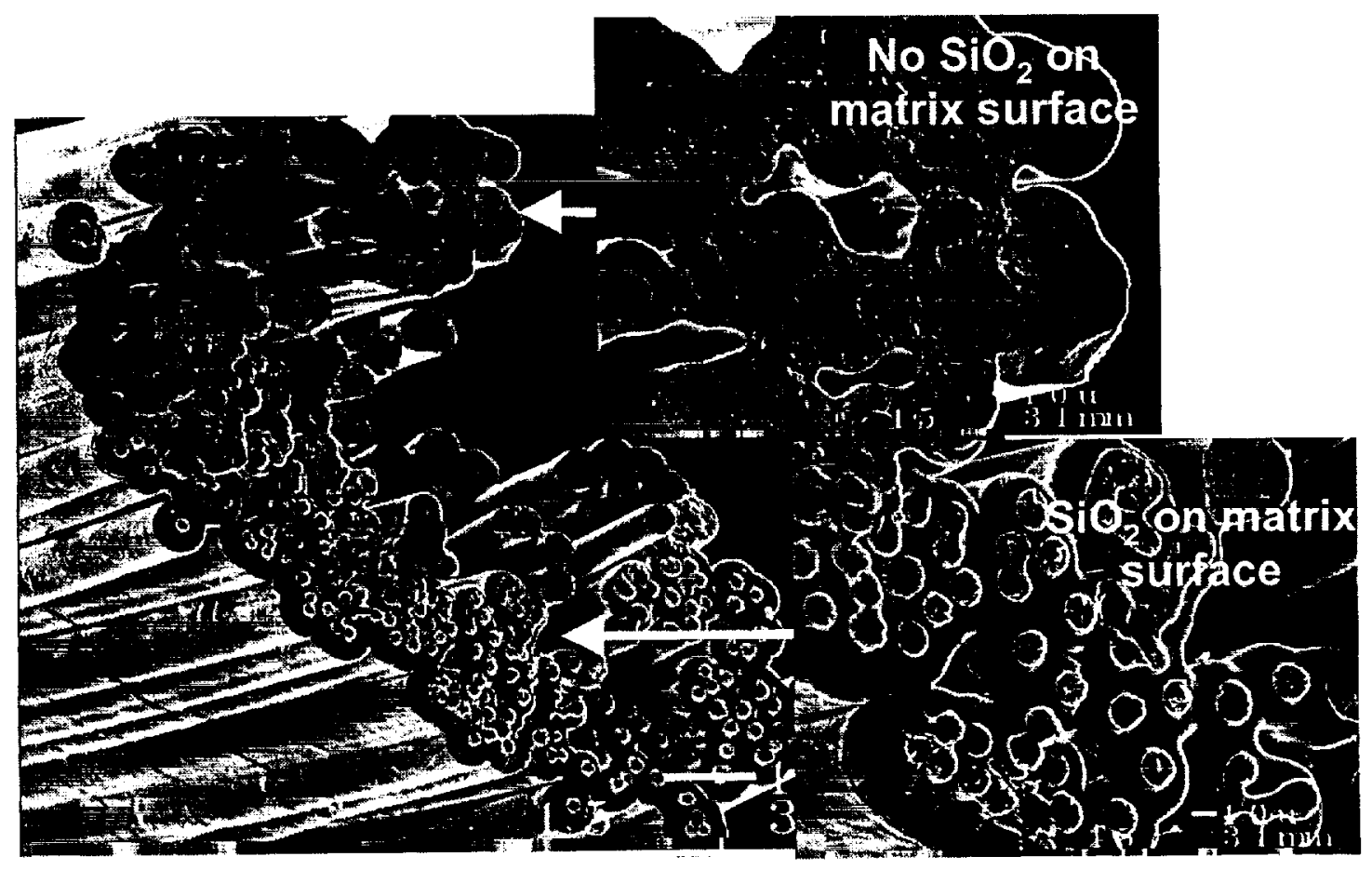

Fig. 7 - Fracture surface of a C-HN minicomposites for stress rupture at $1200^{\circ} \mathrm{C}(439 \mathrm{MPa}, 217 \mathrm{hrs})$. 


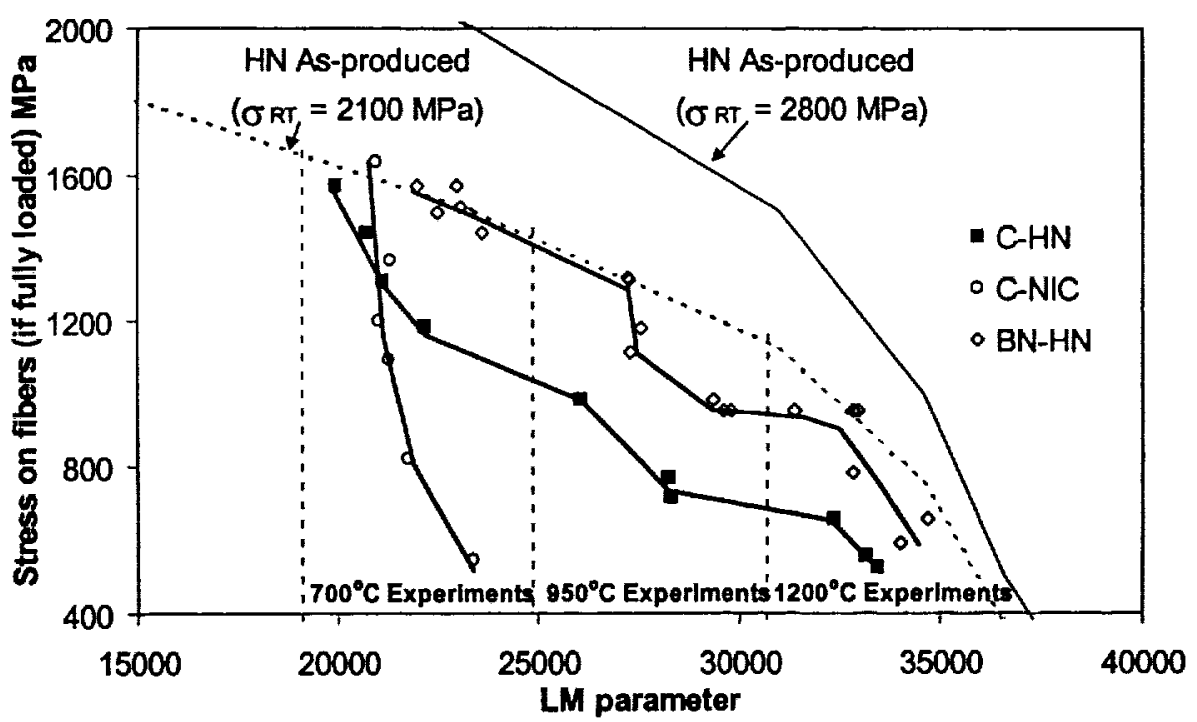

Fig. 8- Plot of the stress on fibers if fully loaded versus LM parameter. Previous data included [2]. See text for further discussion. 


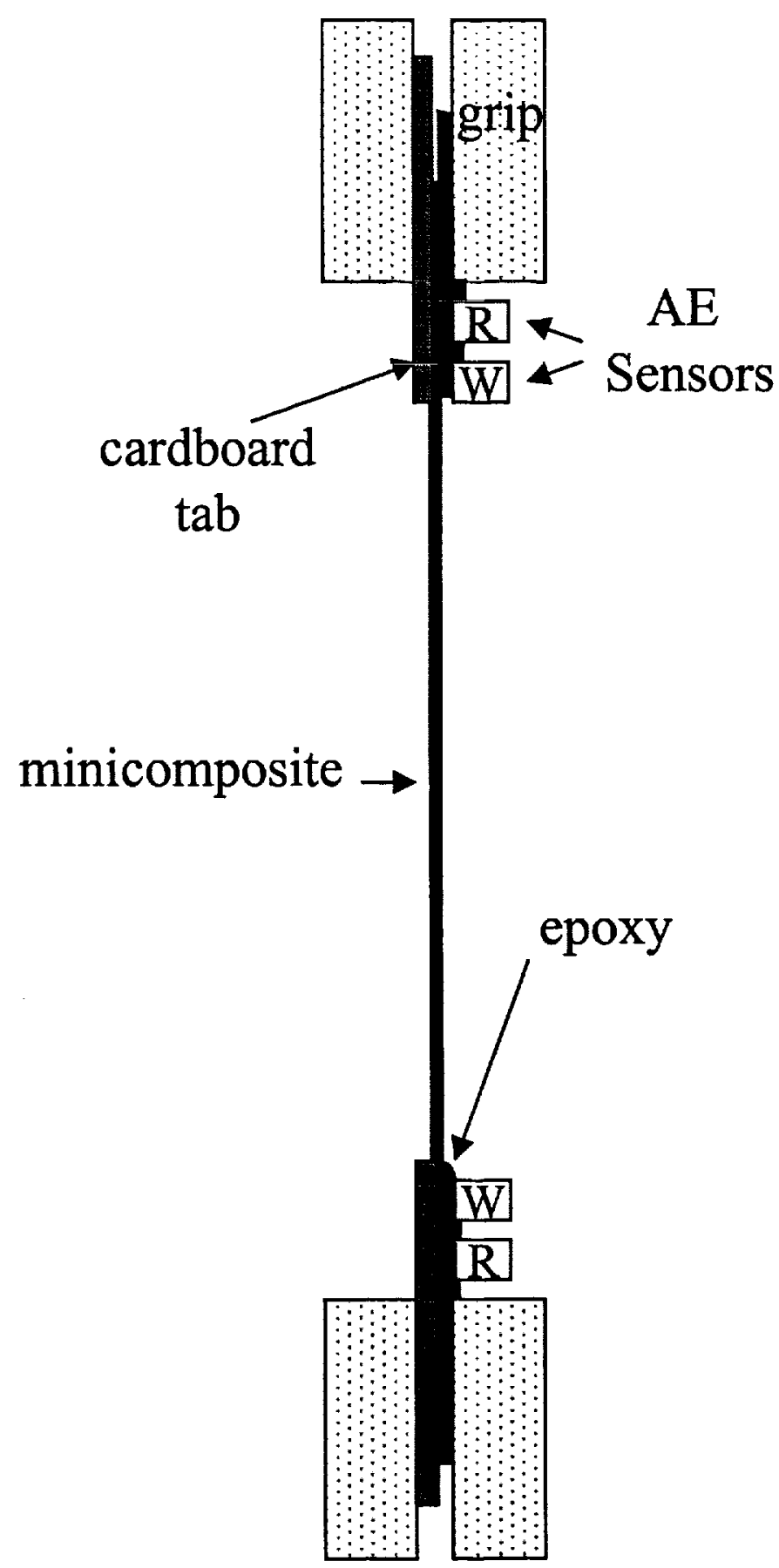

Figure A1: Schematic representation of AE sensor placement on tensile specimen. $\mathrm{R}=$ resonant frequency transducer and $\mathrm{W}=$ wide band transducer. 


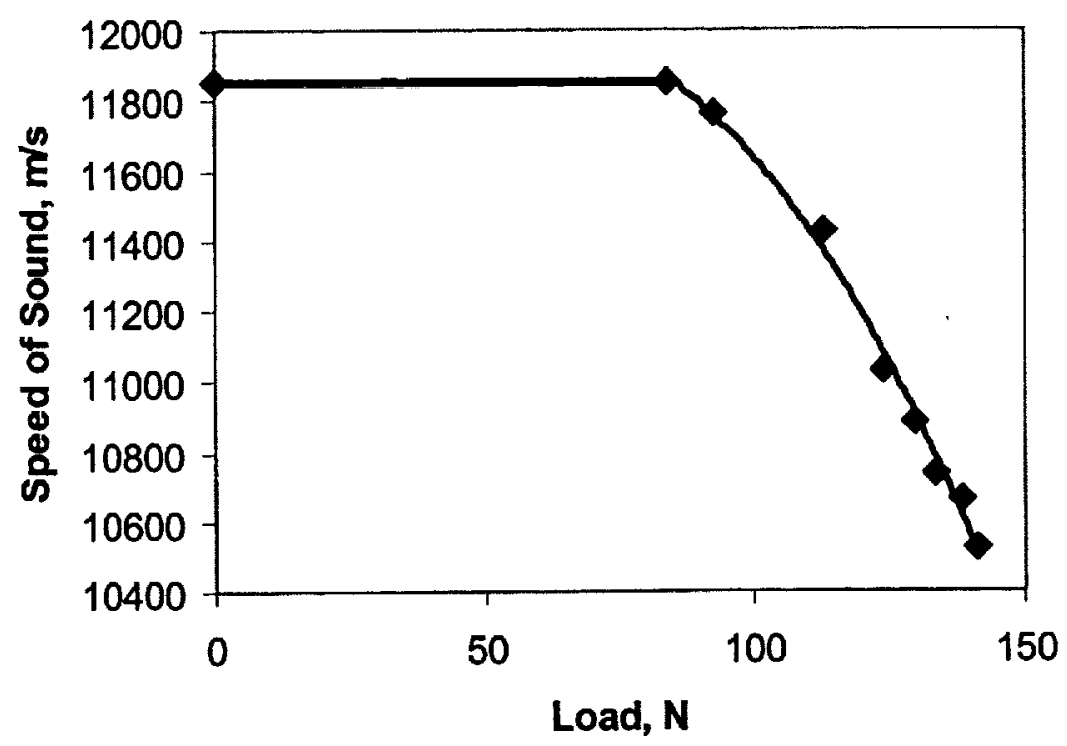

Figure A2: Speed of sound versus load for specimen h3hc70. 


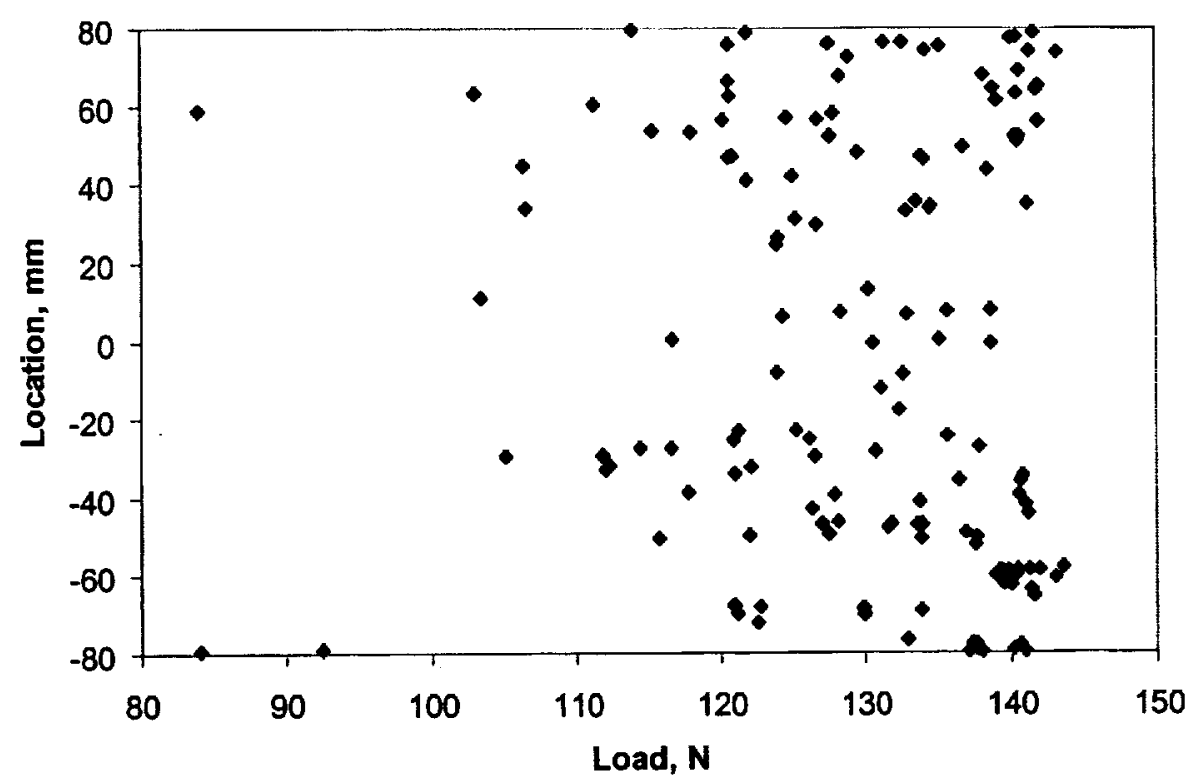

Fig. A3- Location of the AE events along the length of the minicomposite (h3hc70) during a tensile monotonic loading test as a function of time. 
